\title{
Editorial:
}

\section{Special Issue: Environment and Education}

\author{
KAто, Morimichi* \\ Special Editor
}

Without doubt, environmental problems are among the greatest challenges to mankind in the $21^{\text {st }}$ century. Recently, this has become an important issue through the discussions in and around COP 21. But, this is not a completely new issue. Since the publication of Silent Spring by Rachel Carson (1962), environmental pollution has been seen as a threat to our future. In 1970's, through the writings of thinkers such as Gregory Bateson and Arne Naess, environmental problems have been shown to be an issue that concerns our way of life and not just an academic problem in applied science and political economy. However, this sense of crisis, so it seems, has not been sufficiently shared in the academic world.

Regrettably, this is also true of the world of education. With some notable exceptions, it was only after the turn of the century that environmental problem became a central issue. This was triggered by the establishment of the Education Decade for Sustainable Development (2005 - 2014). Nevertheless, even now, environmental problem seems to be confined within a special discipline named Environmental Education. Its impact on educational studies as a whole is not yet felt sufficiently. But, if environmental problems have been caused by the human way of life that placed economic prosperity and comfort before coexistence with nature, then it must be said that education too bears a great part of responsibility. This is one of the reasons why educational studies as a whole should regard environmental problems as their own task and actively engage in stopping the process of destruction.

There is also another but not secondary reason that makes environmental problems a central issue for educational studies. Looking back in history, educational thought, from their beginning both in ancient Greece and in ancient China, took nature (Greek physis or Chinese tien 天) as the standard and the model. The ancients interpreted nature as an absolute foundation that cannot be destroyed by human intervention. Nature, in other words, had "ontological priority"1. Even in thinkers of the modern age such as Rousseau, Pestalozzi, and Froebel, to name a few, we find an unshaken trust in nature. It was nature that gave the educational thought of these thinkers orientation without which modern pedagogy might have become a reckless method of human control and discipline. Human activities had to adjust themselves to nature. Otherwise, they were destined to fail. But now, we are facing a completely different situation, unprecedented in history, where this presupposition is being overturned. Nature turned out to be much more vulnerable and fragile than mankind had imagined. It is, so to speak, at the mercy of human intervention. This drastic change requires

* Sophia University

e-mail: 3novem3musae3@gmail.com 
that we should rethink our understanding of education.

So, faced with environmental problems, educational studies have two tasks that are interconnected. First, they must contribute to solve, or at least alleviate, environmental problems. Second, they must, at the same time, be ready to reexamine themselves and transform themselves, if necessary. The first task is practical, the second theoretical.

This special issue aims to take on this double task by publishing articles from diverse disciplines and from different cultural backgrounds. Some are more theoretical while others are more practical but each in its distinct character contributes to thinking about the involvement of educational studies with environmental problems.

1 See Morimichi Kato, “Challenges of environmental problems to the philosophy of education”, Policy Futures in Education, 13, January 2015, pp. 7-19 